\title{
LA MUERTE DEL CABALLERO
}

\author{
Diego Romero de Solís \\ Universidad de Sevilla
}

\begin{abstract}
«Non ha en el mundo libro nin
(escrito nin carta, ome sabio nin necio que de ti bien (departa; en el mundo non han cosa que con

(bien de ti se parta, salvo el cuervo negro, que de ti,

(Muerte, se farta».

(Arcipreste de Hita, Libro de buen amor).
\end{abstract}

\section{RESUMEN}

La percepción de la vida se vincula a la actitud ante la muerte para abrirse a la experiencia estética en torno al Poema de Mio Cid y a las Coplas de Manrique. Los horizontes simbólicos que brotan de la épica y de la lírica acentúan la figura trágica del héroe, del caballero.

Palabras claves: Estética, poética, héroe, vida, muerte.

\begin{abstract}
The idea of life is linked to the attitude towards death, in order to understand the aesthetic experience of Poema de Mio Cid and Manrique's Coplas. The symbolic horizons which grow from the Epic and the Lyric enphasize the tragic character of the hero.
\end{abstract}

Key words: Aesthetic, poetic, hero, life, death.

Aristóteles, al final de su vida, una vez consumada la etapa metafísica y el apasionado final «científico», acaso solo y cansado, pero sin duda más sabio, más lúcido, pronuncia, a manera de testamento final, estas palabras: «cuanto más solitario y abandonado a mí mismo me he ido encontrando, me he vuelto más amigo del mito». No se trata, me parece, de una tentación irracionalista en un filósofo tan decididamente racional sino más bien una manera de volver a la palabra «poética», a la lectura del mundo como un texto inagotable y a la intuición de la infinitud que late en el propio lenguaje. Hacerse más amigo del mito es hacerse más amigo de la poesía y dejarse llevar 
por la sabiduría de la nostalgia, por el dolor que produce la constante tensión entre conocimiento y felicidad. Y de la misma manera que Aristóteles no quiere alejarse de la realidad (el mito es realidad y apoyo del solitario, de su melancolía), el poeta, en su afirmación del mundo, tampoco lo desea. Este ensayo pretende adentrarse en la experiencia poética, mítica, que brota de dos grandes poctas medievales. El primero nos lleva a los orígenes de la lengua castellana, a su fuente, en un poema admirable, homérico; el segundo, a su final, cuando el medioevo europeo se abre a una nueva experiencia estética, y otro poeta, otro noble caballero, es capaz de estar a la misma altura estética.

El Poema de Mio Cid hace coincidir la primera manifestación literaria de nuestra lengua con la poesía, y durante siglos será la poesía narrativa, tal vez por el magisterio del Poema, el género literario más importante en España. Nuestros primeros poetas, como dice Salinas, no interpretan, ni preguntan, ni idealizan: se limitan simplemente a contar, a relatar. En España, como en todas partes, la poesía medieval es heroica, pero su distintivo esencial es la exactítud histórica. El poeta canta la proeza y la hazaña. De ahí su nombre: Cantar de gesta. La vida no heroica apenas existe como materia poética, y, si aparece, lo hace en forma narrativa. La realidad es lo que pasa, la acción, la silueta del mundo, el grito de la guerra, de la hazaña. La realidad usurpa el protagonismo de la idealidad de la conciencia e inspira el lenguaje de la objetividad. La vida está copiada de la realidad, aunque siempre envuelta en la aureola de la fantasía. ${ }^{1}$ No obstante, el relato en el Poema no se deja llevar por la magia de un Ienguaje meramente fabulador. Lo que caracteriza a su palabra es una sorprendente voluntad de ajustarse a la realidad, de reflejarla con la mayor precisión, hasta el punto que el único elemento maravilloso, pero fugaz, es la aparición del ángel Gabriel al Cid. Hay elementos ficticios, como mostró Menéndez Pidal, así el suceso de las arcas llenas de arena que el Cid deposita en casa de los judíos burgaleses, diciéndoles que estaban llenas de oro, con objeto de obtener un préstamo a cuenta de esa garantía. Un ardid que aparece en multitud de cuentos e incluso viene reseñado en las Partidas. No deja de ser, por tanto, un tópico. Lo original del Poema en este punto es su dimensión ética (junto al engaño está la promesa del poeta de que el Cid pagará con generosidad). No me parece contradictorio este ideal con los hechos, porque no hay voluntad de realidad sin dimensión moral. No se puede construir la casa, el hogar, de la realidad sin los latidos de un corazón que la estructure, que la haga sentir como propia. En el siglo XIII, con la refundición del Cantar, conocida por las Crónicas, se introducen nuevas puntualizaciones respecto a este asunto. El Cid envía a Martín Antolínez, el mismo que había negociado el préstamo sobre las arcas de arena, para que pague a los judíos. Esto se clarifica en el Romancero del Cid con los siguientes versos:

«rogarles heis de mi parte que me quieran perdonar, que con acuita lo fice de mi gran necesidad; que aunque cuidan que es arena

1. V. Salinas, Pedro: La realidad y el poeta. Versión castellana y edición a cargo de Soledad Salinas de Marichal. Barcelona, Ariel, 1976. Este articulo parte de las páginas que dediqué a la actitud del poeta ante la realidad en mi libro Poiesis. Sobre las relaciones entre filosofia y poesía deste el alma trágica. Madrid, Taurus, 1981. 
lo que en los cofres está, quedó soterrado en ella el oro de mi verdads. ${ }^{2}$

Hay otros elementos ficticios, como el episodio del león que el Cid tenía enjaulado y que se escapa por el alcázar de Valencia, lo que provoca que los infantes de Carrión se escondan horrorizados, mientras el héroe se dirige a la fiera, que se deja conducir mánsamente a la jaula. No es, desde luego, un tema original, pero tampoco tiene importancia en el Poema. El autor recurre a muy pocos elementos ficticios o novelescos. Sorprende, por el contrario, los versos de extraordinario realismo, precisos, exactos, concebidos por un poeta con una visión clara y decidida, como en estos versos, en los que describe la entrada del Cid en Burgos:
«Mio Cid Roy Diaz por Burgos entróve, en sue compaña sessaenta pendones;
exien lo veer mugieres $\mathrm{e}$ varones, burgueses e burguesas, por la finiestras sone, plorando de los ojos, tanto avien el dolore.
De las sus bocas todos dizian una razone:
«Dios, qué bien vassallo, si oviese buen señore $\rangle^{3}$

La belleza de la imagen incrementa la sensación de realidad, como cuando el poeta crea como señala Salinas - la primera metáfora de la poesía castellana, una metáfora que es más que una opción ante la realidad, una especie de compromiso vital, la del poeta que sabe la existencia del sufrimiento, que conoce el dolor, y que lo expresa en el adiós del Cid a su familia.

«Llorando de los ojos, que non vidiestes atal, assís parten unos d'otros commo la uña de la carne». ${ }^{4}$

Todo el canto aspira a la exaltación de lo real incluso desde la propia belleza interna y externa del poema. El poeta canta ese momento, tan adecuado para el derroche de la fantasía, como lo es la llegada de la aurora, la aparición de los primeros rayos de sol. El verso brota, una vez más, concreto y preciso.

«Ya criaban los albores e vinie la mañana,

ixie el sol, Dios, qué fermoso apuntava». ${ }^{5}$

2 V. Poema de Mio Cid, edición a cargo de Ramón Menéndez Pidal. Madrid, Ediciones «La Lectura», Clásicos castellanos, 1922 (cit. en la Introducción de Menéndez Pidal). Utilizo también las ediciones de Ian Michael, Madrid, Castalia, 1991 ( $5^{\mathrm{a}}$ edición), y Alberto Montaner, Barcelona, Crítica, 1993 ( $2^{\mathrm{a}}$ edición revisada). Respecto a la figura del Cid he utilizado el libro de Richard Fletcher El Cid, trad. de Javier Sánchez García-Gutiérrez. Madrid, Nerea, 1999.

3 op. cit., versos $15-20$.

4 Versos 373-375.

5 Versos 456-457. 
Como recuerda Salinas, siguiendo a Menéndez Pidal, la principal característica del Poema es la consideración del héroe como hombre que ya, incluso desde el comienzo de sus aventuras, no es concebido de manera fantástica, como es el caso de Roldán, sino que explícitamente se le reconoce la necesidad de lo más elemental para poder subsistir, la justificación de su profesión de guerrero:

«de Castiella la gentil exidos somos acá, si con moros no lidiáramos, no nos darán del pan», ${ }^{6}$

La vida hay que afirmarla. La épica acentúa la vida, porque insiste en la identidad (mundo y acción es lo mismo, como lo es también realidad y voluntad). El poeta épico permanece inalterable ante lo real, ante ese mar que repite su movimiento, su sentido, ante los latidos internos, que se intensifican con la acción, con las reclamaciones del exterior. La lírica, por el contrario, acentuaría lo interior, las regiones de la conciencia, la quebradiza intimidad, reino de la desazón y el miedo. El poeta puede contemplar el choque de las armas, los guerreros relucientes, el estruendo del combate, la sangre derramada que invita a reduplicar el golpe, y el brillo de los ojos esparciendo el pavor de las bestias, de los hombres. El dolor levanta, de nuevo, la voz del poeta, que fortalece la vida y da sentido al torbellino de la muerte. El héroe poetiza el desinterés de la carne, del deseo, y hace universal la acción, la libera de particularidades, de condicionamientos, de temblores. El héroe es la máxima razón, la inteligencia que ha llegado al fondo de la carne, que se hace completamente cuerpo, mundo. El absurdo de la intimidad se abre al sentido del torrente, de la carga de la caballería, al optimismo de las lanzas. «El espíritu guerrero - escribe Ortega comparando los diferentes tiempos históricos - parte de una sensación vital contraria a la que late bajo el espíritu industrial. Es, como he dicho, un sentimiento de confianza en sí mismo y en el mundo que nos rodea. No es extraño que condujese a una concepción optimista del universo. Porque, en efecto, se da la paradoja de que la Edad Media, que una estúpida historiografía nos ha pintado como un tiempo tenebroso y lleno de angustia, ha sido la sazón de las filosofías optimistas, al paso que en nuestra Edad Moderna apenas si han resonado más que las de pesimismo. ¿Es que el espíritu guerrero confía en sí por ignorar los males del mundo? De ninguna manera: conoce tan bien como Schopenhauer todo el dolor cósmico, prevé el riesgo y subraya la angustia de vivir. Pero ¡ahí está!... Ante el mismo hecho, ante la misma realidad del dolor y el

6 Versos 672-673. "Es comprensible —escribe Francisco Rico- que para esas gentes el Cid fuera el héroe por excelencia. En definitiva, lo que cuenta la primera mitad del Cantar es una larga incursión guiada por un adalid con todas las virtudes que para el puesto se requerían y apreciaban, desde interpretar el vuelo de las aves hasta cuidar cada detalle del combate, y rematada por unos beneficios espectaculares para todos: « a cavalleros e a peones fechos los ha ricom (v.848), «el oro e la plata iquiẻn vos lo podría contar? (v. 1214). Una incursión, por otro lado, coronada por una conquista como muchas en las que intervinieron las milicias concejiles y proseguida hasta unas tierras no más distantes que las que algunas asolaban. Los enemigos del Cid temían que cualquier noche se plantara uallá dentro en Marruecos» a darles «salto", a pasar el país a saco, pero él no pensaba embarcarse en operaciones tan insensatas (wv, 2499 y ss.). En 1172 , en cambio, un grupo de caballeros de Ávila no śólo se proponía expulsar de España a los sáracenos, sino acosarlos hasta Marnecos y continuar después hasta Jerusalén... El Campeador de la ficción dejâba volar la fantasía menos que algunos guerreadores enardecidos por la realidad de la frontera". V. Cantar de Mio Cid, edición de Alberto Montaner, Introducción, pág. XX. 
peligro, la actitud espontánea es opuesta. El ánimo guerrero, lleno de magnífico apetito vital, se traga la existencia sin pestañear, con todo su dolor y su riesgo dentro. Son éstos reconocidos de tal suerte como esenciales a la vida, que no se ve en ellos la menor objeción contra ésta, y, en consecuencia, se cuenta con ellos y, en vez de organizar las cosas con la casi exclusiva mira de evitarlos, se los acepta. Esta aceptación del peligro que lleva, no a evitarlo, sino a correrlo, es precisamente el hábito guerrero, es la casa como castillo». ${ }^{7}$ El héroe épico vive inmerso en la presencia del día, en la gesta diaria de la victoria, de la batalla. El héroe es razón de belleza y de impulso. Como dice Salinas, a lo largo del Poema hay una palabra que se repite sin cesar, como un estribillo, lleno de fuerza: cabalgar, cabalgar. El Cid incita constantemente a sus hombres a cabalgar. Esta palabra, piensa Salinas, difunde a través del poema una impresión de movimiento continuo, de la necesidad constante de estar alerta, a caballo, en el esfuerzo sostenido de la conquista. «A cabalgar!,jA cabalgar!», es el grito que define la lucha del siglo XII por la vida. El esfuerzo del hombre, el incansable ejercicio de su voluntad, la tarea diaria de vivir con la dignidad que se siente en desde la intensidad de una vida de héroe, asoma en el Poema de Mio Cid como la llamada a la oración, al deber del amor que a veces se escucha en la cítara. «Pero por una extraña asociación de ideas, muchas veces, al leer un maravilloso poema moderno en el que se encuentra concentrada toda la sutileza y profundidad del pensamiento moderno, Le cimetière marin, de Paul Valéry, al llegar al famoso verso invocatorio - Le vent se lève!... Il faut tenter de vivre! - he recordado las palabras de ese poema primitivo, tan sencillo y directo: "Adelante, adelante, hay que cabalgar!". En nuestro poema la invocación suena como un trompazo que llamara a los hombres a su tarea vital y les exhortara a seguir viviendo y ganándose el pan. $Y$ en toda España el verbo "cabalgar" evoca la imagen completa del hombre medieval, con su caballo, el primer hombre que se distingue de los demás: el caballero». ${ }^{8}$

Menéndez Pidal muestra en su edición comentada del Poema la fidelidad del poeta a la realidad, a la historia y a la geografía. La necesidad de identidad queda fortalecida en la guía del poeta épico, en la canción de gesta. «La exactitud del juglar - escribe - se aprecia cuando, atendiendo a la topografía especial de Castejón comprendemos mejor la sorpresa con que el Cid conquista la villa. Hasta los adjetivos usados por el poeta se hallan hoy exactos: Atienza, una peña muy fort, aún nos parece como tal, pues conserva su imponente castillo, que arranca de la peña, cortada a pico. Fiándonos en esta exactitud habitual, podemos otras veces comprobar con lástima cuánto ha cambiado el aspecto del terreno: la fiera sierra de Miedes encerraba en sí más de una selva maravillosa e grand, que ha desaparecido; el gigantesco robredo de Corpes, cuyas ramas se hundían en las nubes, no es más que un páramo donde el arado desentierra algún grueso tocón, único resto del viejo arbolado; los montes de Luzón, que el juglar describe como fieros e grandes, y la mata de Taranz, antes temerosa para el caminante, son hoy tierra rasa, donde apenas crecen sino humildes cambrones y sabinas; por todas partes el hacha egoísta, imprevisora, ha hecho desaparecer seculares bosques, atrayendo la sequía sobre ambas mesetas castella-

7 Ortega y Gasset, J.: Notas de vago estio, en Obras completas, vol. II, Madrid, Revista de Occidente, 1966 (séptima edición), pág. 430-431.

8 Salinas, op. cit., págs. $46-47$. 
nas». ${ }^{9}$ El poema, además, es inestimable para el conocimiento de las costumbres de la época. La venganza, por ejemplo, con el predominio de las pasiones en aquella sociedad primitiva y huella inquietante en la de hoy, que la hereda. Para Menéndez Pidal la poesía es fuente de la historia y đe manera especial este poema. ${ }^{10} \mathrm{La}$ épica representa la vida exterior, el torbellino de la brutalidad y de lo irracional que invade cada aspecto de la vida (San Bernardo pretendía transformar a aquellos guerreros sedientos de sangre y codicia en caballeros que apostaran por la bondad y la bellcza; los puntos luminosos de los monasterios cistercienses que configuraban el mapa de Europa respondian al mismo espíritu, porque también lo bueno y lo bello habrían de surcar a la propia naturaleza). La venganza era un derecho y la simple ira del rey era causa suficiente para el destierro y la confiscación, sin que hubiera proceso, ni juicio, ni siquiera defensa. La épica recoge la irracionalidad que cada época lleva consigo, pero también la palabra imaginativa, el cabalgar continuo de un pueblo, que lo sostiene y que lo lleva hacia adelante, hacia el ritmo de la vida. Lo que permanece, decía Hölderlin, lo fundan los poetas. El canto a la realidad se transforma en afirmación de lo nacional como lo popular. Así pensaba Federico Schlegel (el nacionalismo acaso sólo encuentre verdadera justificación en la dimensión estética, que lo hace perdurar y lo convierte en cultura, al transformarlo en sentimiento artístico). No se trata de la identificación con el poder, con las instituciones, con la pretensión de hacer Estado, de repetirlo o multiplicarlo. No, lo popular tiene que lograr, para serlo, la elevación poética que hace posible la expresión de las cualidades de un pueblo, de sus valores conscientes e inconscientes. «España - escribe Schlegel- con el histórico poema del Cid tiene una ventaja peculiar sobre otras muchas naciones; es éste el género de poesía que influye más inmediata y eficazmente en el sentimiento nacional y en el carácter de un pueblo. Un solo recuerdo como el del Cid es de más valor para una nación que toda una biblioteca llena de obras literarias hijas únicamente del ingenio y sin un contenido nacional». " Una generosidad que sólo se da en ese espacio vital donde la vida es difícil, en el límite, en la frontera (donde el peligro acecha, y se cumplen las amenazas reales y míticas, y que es transitada, cruzada por miles de seres humanos: soldados, mercenarios, comerciantes, eruditos, refugiados), de la que brota la Castilla democrática y el sueño de su imaginación. Una crítica constante preside el Poema, de abajo a arriba, del pueblo llano y la baja nobleza a la alta, a los grandes, a los fuertes, hasta llegar incluso al propio rey. El espíritu que lo preside es la imaginación de lo real y la idea caballeresca de la persecución de lo bueno y de lo bello. El poema ha incorporado los valores morales del alma aristocrática y el desprecio a todo lo vulgar. El poema reclama el deber ser del sistema señorial y lo critica al mismo tiempo:

9 Menéndez Pidal, op. cit., pảgs. $88-89$.

10 No entro a discutir si el Poema es una adecuada fuente histórica, sobre todo para fundamentar la hermosa tesis de Menéndez Pidal en torno a su significado nacional. La tesis de este brillante historiador fue tergiversada por la ideología del franquismo que quiso establecer una unión entre el Cid y el dictador. Todo esto resulta hoy ridículo, aunque para Menéndez y Pidal llegó a ser seguramente trágico, El Cid es un héroe cristiano y musulmán, para los que también lucha. Es un mercenario que vive de la guerra, de la rapiña, de la violencia, pero sobre todo es un símbolo (estético y no político) que encarna la vida heroica y la intuición de vivir en un horizonte físico, vital, acaso no sólo geográfico sino espiritual, España, donde aspiran a sobrevivir cristianos, musulmanes y judios. Estos símbolos estéticos marcan la identidad cultural de una nación.

11 Cit. en op. cit., en Introducción de Menéndez Pidal, 
“Dios, qué buen vasallo se oviesse buen señor!". El espíritu democrático, como hace valer Menéndez Pidal, es encarnado por el Cid, por un hidalgo despreciado por la alta nobleza y abandonado por su rey, y que, sin embargo, lleva a cabo las más grandes hazañas y ve cómo sus hijas llegan a ser reinas. ${ }^{12}$ El héroe encarna también en su ambición algo más noble que su propia voluntad de poder: la imaginación democrática de un pueblo que se levanta desde la lucha constante. El espíritu democrático, colectivo, de transformación se hace símbolo nacional, principio de identidad de un pueblo que necesita abrirse al espacio y al tiempo, y hacerse categoría real a través de lo estético. «La edad heroica es la edad primitiva vivida por algunos pueblos que, impulsados por una elevada concepción nacional, sienten colectivamente la necesidad de una activa información sobre sus sucesos actuales o pasados, y no conocen el uso de la escritura; entonces, sólo pueden divulgar y conservar sus noticias de actualidad y sus relatos históricos, dándoles fijeza estable por medio del verso y dándoles valor por medio del canto. La epopeya, pues, es la historia oral, cantada por un pueblo que carece de historia escrita; es la historia poética que idealiza los héroes de ese pueblom. ${ }^{13}$ Se trata de la propia colectividad que mira hacia el otro lado de las cosas, hacia lo que no existe. El cantar de gesta grita la libertad que lleva consigo una promesa de igualdad y de reparto del poder (la creación artística cumple a veces su destino desinteresado y la experiencia estética protagoniza la instantánea revelación de este conocimiento esotérico). El Cid encarna la libertad y el espíritu, la libertad y la libido. ${ }^{14}$ «El culto del héroe ha sido necesario no sólo por la existencia de las guerras, sino a causa de las virtudes que el herósmo comporta y que, siendo advertidas seguramente desde los tiempos prehistóricos, hubo necesidad de exaltar, resaltar y recordar. La magia, el aparato, el esplendor del mismo vestuario guerrero de los antiguos así lo proclama, como la coronación de los vencedores equiparados a reyes. La relación entre la «pequeña guerra santa», es decir, entre la lucha contra los enemigos exteriores y materiales, y el combate contra los enemigos interiores y espirituales, determinó automáticamente la misma relación entre el héroe de una y otra guerra. Todas las cualidades heroicas corresponden analógicamente a las virtudes precisas para triunfar del caos y de la

12 «Su familia era aristocrática -escribe Fletcher refiriéndose al Cid-, Es importante insistir en ello porque en este siglo de multitudes se ha tendido a "democratizar" la figura del Cid y a darle la imagen, hoy atractiva, de alguien que partiendo de la miseria llegó a la riqueza. Es cierto que prosperó, pero la base social de la que procedía no era humildes, op. cit. págs. $111-112$.

13 Menéndez Pidal, Ramón; La España del Cid. Madrid, Espasa-Caipe, 1967, pág. 582.

14 El Cid parece tener, para la época que vivía, un considerable interés por el mundo del espiritu. Escribe Fletcher: «A Rodrigo, pues, no le faltaba preparación intelectual. Ibn Bassam nos proporciona una imagen sorprendente y verídica, puesto que procede de una fuente enemiga, de los últimos años de su vida. "Se dice que en su presencia se estudiaban libros: se le leían las hazañas guerreras de los antiguos héroes de Arabia, y al llegar a la historia de Mohallab se llenaba de gozo y expresaba toda su admiración por este héroe". Se trata, además, de una información interesante sobre cómo llenaba sus horas de ocio el conquistador de Valencia. (Habria que preguntarse si las historias se las léan en árabe. Rodrigo probablemente había adquirido al menos los rudimentos de esa lengua durante su destierro en Zaragoza. Hugo Bunel, que fue desterrado de Normandia después de haber decapitado con un hacha a Mabel de Bellême mientras dormía, vivió durante veinte años entre los sarracenos, estudiando sus costumbres y su lengua; como consecuencia de ello, pudo prestar valiosos servicios a los ejércitos de la Primera Cruzada). La afición de Rodrigo por las narraciones heroicas debió setle inculcada a una temprana edad mediante relatos biblicos, leyendas de santos e historias del pasado hispánico, junto al sentimiento de orgullo por las hazañas de sus antecesores. Una virtud marcial atemperada por una tosca moralidad cristiana era lo que los nobles del siglo XI buscaban infundir en sus hijos» (op. cit. pág. 113-114). 
atracción de las tinieblas. De ahí que el sol se asimilara en muchos mitos al héroe por excelencia. Por esta causa, en las monedas aparece Alejandro el Grande con los cuernos de Júpiter Ammón, es decir, identificado con el sol pujante de la primavera, bajo el signo de Aries. Por ello dice Jung que el más egregio de los símbolos de la libido (y pudo decir del espíritu) es la figura humana como héroe, objeto de mitos, leyendas y relatos tradicionales. Y también que en el destino del héroe coinciden lo histórico y lo simbólico. El héroe tiene como fin primordial vencerse a sí mismo; por eso en las leyendas germánicas los héroes suelen tener ojos de serpiente. En el mito de Cécrope, el héroe es mitad hombre y mitad serpiente. La cristianización del héroe lo convierte en caballero, bajo la advocación de los santos guerreros, como san Jorge y san Miguel arcángel». ${ }^{15}$

Los ideales democráticos vinculados al Cid parecen tener raíces religiosas. El mesurado tratamiento de la venganza sorprende en compraración con otros poemas épicos de la época. El honor familiar del Cid se reivindica en un duelo presidido por el rey que termina no con el descuartizamiento de los traidores sino tan sólo con la declaración legal de su infamia. La venganza es sustituida por la reinvindicación caballeresca del honor. El Cid, a pesar de ser víctima de una persecución injusta por el rey, se comporta de manera real y generosa. La épica exige un encuentro entre ética y estética, que, más tarde, ilumina múltiples instantes del poema. El sacrificio de Aquiles es admirado y premiado por los dioses. El campo de batalla deja ver no sólo los valores técnicos de la guerra sino también la pasión de la subjetividad, el amor y la belleza. Como subraya Salinas, sorprende en el poema, el equilibrio, la proporción entre la realidad misma y el arte de crear una nueva realidad poética. La afirmación del principio de identidad va acompañada con el aura de lo sensible, «una realidad espiritual que surge al observar atenta y amorosamente el mundo real como fuente de lo poético, como si sintiera el poeta que de su constancia al ceñirse a las fuentes, paso a paso, surge la poesía» ${ }^{16}$. La diferencia se hace imaginación, el grado de vida ético-estética integrado en la misma: aquí se distingue tanto el hombre esteta (creando y contemplando la belleza artística) como el moral (atreviéndose a vivir desde la diferencia de lo ético). El vínculo ideal del héroe con su pueblo, como dice Menéndez Pidal, ha de seguir indisoluble. «La ejemplaridad del Cid puede continuar animando nuestra conciencia colectiva, y en lo futuro, como en lo pasado, guardarán alto sentido las sencillas palabras en que el anónimo poeta, patriarca de nuestra literatura, formuló la mística unión del héroe con su España. «A todos alcanza ondra por el que en buen hora nació». Siempre la vida histórica del héroe puede ser ejemplo que nos haga concebir la nuestra como regida por un deber de actividad máxima, de justicia constante, de mesurada energía; siempre requerirá de nosotros esa heroicidad oscura, anónima y diaria, única base firme del engrandecimiento de los pueblos y sin lo cual el heroísmo esplendente no tiene base; siempre nos mostrará los más seguros rumbos de la ambición personal hacia los ideales colectivos del grupo humano a que estamos ligados y dentro del cual nuestra breve vida recibe un valor de eternidad» ${ }^{17}$. En un tiempo de indigencia moral y vital como el nuestro, el Poema parece que invita a

15 V. voz «héroe» en Cirlot, J.E.: Diccionario de símbolos. Madrid, Siruela, 1997.

16 Salinas, op. cit., pág. 55-56.

17 Menéndez Pidal, op. cit., pág. 552. 
beber en la fuente de la inspiración y el sueño. La palabra muestra en la epopeya su identidad con el mundo, su capacidad para conquistarlo. La paradoja que iguala la diferencia con la identidad brota de una imaginación que pretende una mímesis de lo vital, el movimiento colectivo de una vida ascendente hacia la luz de unos ideales que logran trascender cualquier tiempo y que se incrustan, como obras de arte, en la memoria colectiva de la poesía épica: la justicia, la igualdad, la dignidad, o la melancolía del caballer ${ }^{18}$.

\author{
«De los ojos tan fuertemente llorando, \\ tornava la cabeca i estávalos catando. \\ Vio puertas abiertas e ucos cañados, \\ alcándaras vázias sin pielles e sin mantos \\ e $\sin$ falcones e sin adtores mudados. \\ Sospiró mío Cid, ca mucho avié grandes (cuidados. \\ Fabló mío Cid bien e tan mesurado: \\ i"grado a tí, Señor padre, que estás en (alto! \\ "Esto me an boulto mios enemigos malos" $\gg\left({ }^{19}\right.$.
}

La dimensión estética cobija también la silueta de la muerte. La obra de arte, cuando realmente lo es, no rechaza el dialogo con ella, no podría hacerlo, porque además de aceptar su sombra, brota del encuentro con ella en los momentos en donde el creador comprende el destino de la palabra y lo que en verdad la inspira. La obra de arte está llena de sufrimiento, pero de un dolor sublimado, de un miedo que apenas se nota, como una insignificante brizna que apenas mueve una hoja. A veces, el poeta decide enfrentarse a la muerte cara a cara y la realidad misma se transfigura desde su cercanía a la muerte, se destacan los límites que la circundan y brillan esas intuiciones que vuelven a encender la vida porque han tocado fondo en la existencia humana. Este es el caso de las Coplas de Jorge Manrique. En cierto modo, como ya dije ${ }^{20}$, es también un texto muy conocido, pero como clásico vivo, actual, siempre brota algo nuevo para la vivencia en cada lectura atenta. Con Manrique

18 «En el Occidente cristiano - escribe Hegel- la relación feudal y la caballería son el terreno para el libre heroísmo y para las individualidades que estriban en sí. De esta índole son los héroes de la Tabla Redonda, así como el círculo de héroes cuyo centro constituye Carlomagno. Como Agamenón, Carlomagno está rodeado de figuras heroicas libres y es por tanto una cohesión igualmente impotente, pues constantemente debe convocar a consejo a sus vasallos y está obligado a ver cómo estos siguen igualmente sus propias pasiones, y ya puede tronar cual Júpiter en el Olimpo, que le dejan en la estacada con sus empresas para correr aventuras cada cual por su cuenta. El modelo más acabado aún de esta relación lo encontramos en el Cid. También éste es miembro de una liga, depende de un rey y tiene que cumplir con sus deberes de vasallo, pero a este nexo se opone, como la voz irresistible de su propia personalidad, la ley del honor, por cuyos inmaculados esplendor, nobleza y fama lucha el castellano», Lecciones sobre Estética, trad. de Alfredo Brotóns Muñoz. Madrid, Akal, 1989, pág. 138.

19 Versos, 1-9.

20 Romero de Solís, D.: Poíesis. Madrid, Taurus, 1981. 
han transcurridos tres siglos nada menos y la poesía se ha vuelto cortesana, con mezcla del elemento guerrero (Manrique muere en el asalto a un castillo del marqués de Villena, que está en guerra con los Reyes Católicos) y de la sensibilidad que se despierta con el Humanismo, con la vida cultivada y exquisita del Renacimiento, aunque también llena de angustia y miedo ${ }^{21}$. La poesía cortesana es el canto de la nobleza, de sus mejores cabezas sensibles que quieren seguir diferenciándose en el combate de la escritura. La identidad, que antes establecían tantos historiadores entre burguesía y creación literaria, tiene sentido, sobre todo, a partir de la categoría de modernidad, establecida por Baudelaire, pero mucho menos en interpretaciones históricas más generales. La creación poética, lo mismo que la filosófica, son sublimaciones aristocráticas, afirmaciones de la diferencia, de los límites, del predominio del espíritu. Esta es la memoria, la enseñanza de Heráclito y Platón, que todavía persiste menos como nobleza de sangre que como mérito, dignidad conquistada a través de la acción y de la reflexión. El poeta, como el filósofo, no pueden ser burgueses, aunque lo hayan sido socialmente. Son marginados, fronterizos, desesperados en sus límites convencionales, y destinados a convertir su imaginación en creadora. El poeta Jorge Manrique también, a su modo, es así, y la lucha, lo mismo que el recuerdo, el origen, iluminan su poética invocación a la muerte:

\author{
«Recuerde el alma dormida, \\ avive el seso y despierte, \\ contemplando \\ cómo se passa la vida; \\ cómo se viene la muerte \\ tan callando; \\ cuán presto se va el plazer; \\ cómo, después de acordado \\ da dolor; \\ cómo, a nuestro parescer \\ cualquiera tiempo passado \\ fue mejor» ${ }^{22}$.
}

Hay, desde el comienzo, una atmósfera espiritual marcada por la nostalgia y la declaración de un principio ontológico que pone en duda la realidad de lo presente, su vivencia, y hace de la percepción de la memoria el caudal de la inspiración. La vida contemplativa, la existencia del caballero de la fe - san Bernardo vuelve a estar presente en la conversión de los guerreros en caballeros de Cristo- parece, por un momento, sustituir a la acción. La conciencia exige otra apuesta, para des-

21 V. Delumeau, J.: El miedo en Occidente. Versión castellana de Mauro Armiño, revisada por Francisco Pérez Gutiérrez. madrid, Taurus, 1989. ¿Por qué ese silencio prolongado sobre el papel del miedo en la historia? Sin duda a causa de una confusión mental ampliamente difundida entre miedo y cobardía, valor y temeridad. Por auténtica hipocresía, lo mismo el discurso escrito que la lengua hablada - ésta influida por aquél — han tendido durante mucho ticmpo a camuflar las reacciones naturales que acompañan a la toma de conciencia de un peligro tras las apariencias de actitudes ruidosamente heroicas. «La palabra miedo está cargada de tanta vergüenza —escribe G. Delpierre-, que la ocultamos. Sepultamos en lo más profundo de nosotros el miedo que se nos agarra a las entrañas»" (Delumeau, op. cit. pág. 12).

22 Manrique, Jorge, Poesía, edición de Jesús Alda Tesán. Madrid, Cátedra, 1977. 
pertar, para poder mirar la llanura de la verdad, y lograr, así, olvidar las percepciones vitales, que claman por la tierra, por los frutos del fango, de la acción. El esfuerzo intelectual de la contemplación, de la negación de la voluntad de vivir, que termina por afirmar la vida, pero de otra clase, la que pertenece al arte, como estética del pesimismo. La vida al enfrentarse a la muerte, al batallarla, niega paradójicamente lo que tenemos, aunque confíe en la esperanza, casi evidente para el poeta, de la vida eterna. Pero, ¿puede hablarse de una esperanza evidente? La esperanza no ve, pero permite la luz, e invita a la imaginación a llenar el vacío de la certeza, de ese saber de cosas concretas, positivas, como la extinción de la vida individual, de las especies, de los mundos, y la invasión de la noche eterna. La poética de Manrique pertenece al escalofrío, a los flujos de la pasión. El plumaje de las alas de los ángeles cristianiza el estremecimiento. La vida, no obstante, llama siempre al placer, vocea su nombre en cada rincón del cuerpo colectivo. El hombre se retuerce, como un olivo a punto de morir, viejo y cansado, en su aspiración de sangre y vino. La temprana conciencia renacentista comenzaba no sólo a experimentar sino a teorizar acerca de los impulsos más telúricos, más arraigados, más justificables. De ahí que el placer recordado, la conciencia del no placer, sea, en efecto, conciencia dolorosa, pero no en cuanto reconstrucción del placer, porque, en cuanto tal, es placer mismo, sino «después de acordado», en su nostalgia, en su falta, en la secuela que deja, en la adormecida (todo el paisaje se vuelve, como la tarde, una aspiración de las horas hacia la noche, como una marea negra que sube venciendo todas las cosas que no son humanas, pero llegan a parecerlo con la fuerza del viento y los voces azuladas de las montañas). La realidad es ahora, como dice Salinas, objeto de una mirada más penetrante, de interrogación y de duda, de un preguntarse por el destino personal. «La actitud analítica ha realizado en el cuerpo de la realidad esa labor de disección mental (casi de autopsia) que el hombre se ve obligado a ejecutar en ciertas épocas de una vida individual o histórica. En el Romancero y en el Cantar de Mio Cid nos parece escuchar el mensaje siguiente: «He aquí la vida; tomadla». En cambio, en Jorge Manrique se nos dice: «¿Qué es la vida?». Por eso nos detenemos al llegar a este poeta como la primera voz imperativa en la historia de la lírica castellana de un ente misterioso que exclamara: «¿Alto!». El poeta ha empezado ya a contemplar la realidad con ojos que no se conforman con lo que ofrecen: la superficie y la apariencia de las cosas; ha dejado tras de sí, sin reparo, las hermosuras exteriores de la vida, sus placeres y sus goces. Y ha tomado el camino hacia dentro de sí mismo, el camino de la interioridad, ese camino que lleva al hombre hacia la otra ladera de las cosas, el reverso terrible del mundo. Jorge Manrique da el primer paso en nuestra lírica hacia la vida interior y su angustia; va derecho, sin duda alguna, al centro mismo del íntimo conflicto de toda vida espiritual»». ${ }^{23}$

Hay una nueva locura, una nueva exigencia inspirada, una nueva actitud, alimentada en la contemplación, en la belleza del mundo, del paisaje, que causa vértigo y sentimiento de culpa, de pecado, porque el placer remonta un vuelo hacia lo alto, y, como un pájaro solitario, desprecia las cosas que se ven en la superficie, e intuye los secretos del cuerpo y la llamada interior de la tierra. Una hermosa locura que responde a la nostalgia de la luz, la inspiradora de las ideas y del arte, una locura que, si bien acepta la realidad, descubre otra realidad, la crea dede la nostalgia, desde la inquieta carnalidad del sueño, y presiente la apariencia de las cosas. 


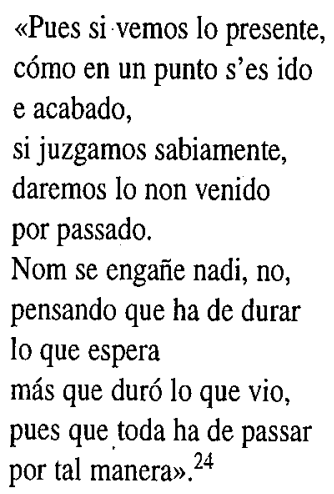

El tiempo parece destruirse, pero ¿cómo aniquilarlo si el tiempo es lo que nos constituye, lo que nos limita, lo que nos devuelve la imagen de la miseria? Sólo la poesía puede destruir ese maleficio. La poesía es libertad, liberación de todas las cadenas, sobre todo, de los grilletes del lenguaje, porque es la palabra que marca el límite, sobrepasándolo. El presente se hace instante y desaparece en su propia fugacidad, pero el poeta añade algo muy importante: daremos lo non venido/por passado. ¿Hacer del futuro pasado?, ¿cómo es posible semejante dislate?, ¿acaso la historia se repite? No lo hace desde la apariencia, desde los hechos, desde los personajes, pero sí desde las motivaciones, desde las causas estructurales, desde las pasiones, desde los anhelos, desde la libido, desde el inconsciente. La historia es el itinerario que recorren el miedo y la angustia en la búsqueda esperpéntica del horror, la moral y la belleza. Los discípulos de Hegel, pensaba, Schopenhauer, al convertir la historia en el asunto principal de la filosofía, deberían tener presente las enseñanzas de Platón, su insistencia en considerar el verdadero asunto de la filosofía lo invariable, lo eterno, y no lo que cambia, lo que hoy es de una manera y mañana de otra. El nacimiento, el devenir, la misma muerte física no son más que fenómenos, cosas que pasan. Sólo las ideas son eternas. El tiempo, en consecuencia, tan sólo es apariencia, como la misma historia (la astucia de la razón guía a la propia historia). La felicidad, el encuentro esperado con el placer, no es más que instante fugaz, ilusión pasajera, y a la postre, dolor y tristeza. La paradoja del tiempo es su idealidad, la impotencia de la utopía que asoma a menudo en su horizonte. Hay un engaño radical en pensar que el futuro durará más que el pasado. El pasado se ha vuelto fugaz, inconsistente, y el futuro sólo quiere abrirse a la angustia. «Así Manrique - escribe Salinas - cierra al hombre la única puerta de escape, la esperanza en lo que no ha pasado aún, el amanecer del futuro, en suma, la puerta a lo posible, lo incalcullablemente posible. $\mathrm{Al}$ término de estas estrofas se siente uno prisionero, encerrado, sin posible salida, dentro de las tres dimensiones del pasado, presente y futuro, que pueden reducirse a una sola verdad: la fugacidad, la temporalidad, la nada. Nuestras vidas se comparan a los ríos, camino del mar, que van recogiendo las aguas de sus afluentes, grandes y pequeños. La muerte es el mar, el gran igualador de los destinos humanos. Y todo eso lo dice el poeta en la forma más grave, más sencilla, sin la menor indicación de vacilación o de queja, como si estuviera por encima de toda debilidad o flaquezas. ${ }^{25}$ 


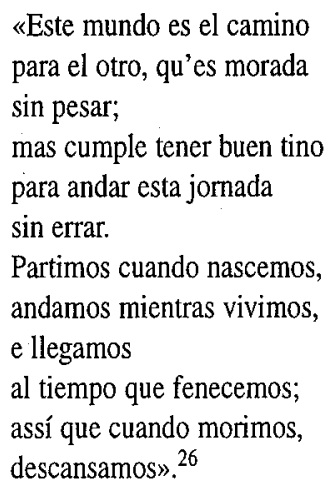

Los primeros versos parecen seguir la concepción cristiana, pero con una cierta influencia del mundo clásico, en esa visión escueta de la otra vida, fría, triste, serena, que recuerdan, en cierto modo, las palabras de los héroes muertos (la aparición de un triste Aquiles ante Ulises) en la Ilíada. La vida de ultratumba («qu'es morada/sin pesar»), porque lo que caracteriza este mundo, según Manrique, es el dolor, la belleza destruida, la apariencia de los placeres, la quiebra de los estados, y el azar de la fortuna. La casualidad casi siempre ha sido un tema marginal para la filosofía, pero de enorme importancia para la literatura. El azar, por ejemplo, une a Manrique y a Fernando de Rojas. Si en la tragicomedia es lo que parece ser fundamento del mundo, el azar en Manrique se cristianiza y se enaltece el espíritu trágico de la nobleza guerrera, del caballero, que se ha cristianizado, pero se hermanan en cuanto concepciones pesimistas del mundo. La respuesta estética de Manrique al miedo del hombre es el teatro de las armas y la seguridad existencial del cristiano viejo. Así, un día cualquiera, la muerte se presenta en la villa de Ocaña y llama a una determinada puerta:

\author{
«diziendo: «Buen caballero, \\ dexad el mundo engañoso \\ e su halago; \\ vuestro corazón d'azero \\ muestre su esfuerzo famoso \\ en este trago; \\ e pues la vida e salud \\ feziste tan poca cuenta \\ por la fama; \\ esfuércese la virtud \\ para sofrir esta afruenta \\ que vos llama». ${ }^{27}$
}

26 Manrique, versos 49-60.

27 Versos 395-408. 
El caballero ha de enfrentarse al amargo trance con el mismo control del cuerpo y del espíritu, que antes tuvo que conquistar, en cada batalla, en cada lance, cada vez que se jugaba la vida. Los caballeros, los herederos de Grecia en su búsqueda de lo bello y de lo bueno, saben de la carnalidad de esta sabiduría, de este conocimiento íntimo, que si no se tiene, no se puede simular, y que para poseerlo hay que practicarlo continuamente, hasta el punto de ser capaces de sacrificar la vida individual en cualquier momento. Esta es la grandeza del héroe y la estética vital del verdadero aristócrata. Sólo la diferencia es la virtud. Nunca, el tener más, ni la suerte, ni lo que digan los otros. La virtud se alimenta en la virtud, en su práctica, como el valor crece y se afirma cada vez que hay que demostrarlo. La buena fama, la de verdad, no es otra que nombrar la vida propia con los mismos valores que aparecían antes en el Poema de Mio Cid. La vida y la salud apenas importan si no es para mantener esa fama, el nombre de lo bello y de lo bueno. El caballero muere, rodeado de su familia, respirando fe y virtud. La poesía se hace ahora cantar de vida y muerte. La conciencia se vuelve creativa y forma la tragedia, la configura, y la creación cumple con su destino de símbolo vital. La muerte, entonces, se puede tragar con severa belleza. La muerte del caballero es la muerte de la tragedia. ${ }^{28}$

\author{
Diego Romero de Solís \\ Departamento de Estética \\ Facultad de Filosofía \\ Av. San Francisco Javier, s/n \\ 41005-SEVILLA
}

28 El destino del héroe es siempre el sacrificio, la muerte, porque es, en cierta forma, el arquetipo de la necesidad que tiene el ser humano de crear ideales trascendentes que encarnen una vida digna, admirable. No hay humanidad sin valores y sin la exigencia inherente a los mismos de extremar lo humano, es decir, llevar a cabo lo heroico. En este sentido, la valentía es una cualidad esencial de lo humano. Kant lo vio muy bien en un texto, poco citado y que no suele interesar, de la Crítica del Juicio: «Porque ¿qué es lo que, incluso para el salvaje, es objeto de la mayor admiración? Un hombre que no se aterra, que no teme, que no huye del peligro, y, al mismo tiempo, empero, va a la obra tranquilo y con total reflexión. Incluso en el estado social más civilizado perdura aquella preferente consideración hacia el guerrero; sólo que se desea además que éste muestre al mismo tiempo todas las virtudes de la paz, bondad, compasión y hasta un cuidado conveniente de su propia persona, justamente porque en ello se conoce la invencibilidad de su espíritu por el peligro. De aquí que, por más que se discuta, en la comparación del hombre de Estado con el general, sobre la preferencia del respeto que el uno más que el otro merezca, el juicio estético decide en favor del último. La guerra misma, cuando es llevada con orden y respeto sagrado de los derechos ciudadanos, tiene algo de sublime en sí, y, al mismo tiempo, hace tanto más sublime el modo de pensar del pueblo que la lleva de esta manera cuanto mayores son los peligros que ha arrostrado y en ellos se ha podido afirmar valeroso; en cambio, una larga paz suele hacer dominar el mero espíritu de negocio, y con él el bajo provecho propio, la cobardía y la malicia, y rebajar el modo de pensar del pueblo; (II, 28. Trad. de Manuel García Morente. Madrid, Espasa Calpe, col. Austral, 1977, pág. 165). La pérdida del horizonte de lo sublime convierte a la tragedia en una farsa, como ha ocurrido en nuestro siglo, y a los individuos les arranca el corazón mismo de la lucidez. 